\title{
'The Science of CAIM: What's Next for Complementary, Alternative and Integrative Medical Research?'
}

\author{
Elizabeth H. Logue
}

UCLA's Office of the Vice Chancellor for Research and Center for East West Medicine recently hosted a symposium on the future of complementary, alternative and integrative medical research featuring nationally recognized speakers. The symposium took place on the UCLA campus in late January and was targeted to the Geffen School of Medicine's Institutional Review Board (IRB). Its purpose was to address the finding by the National Center for Complementary and Alternative Medicine (NCCAM) that IRB's may be unfamiliar and/or uncomfortable with unconventional medical modalities thus apt to disapprove studies of those modalities (1). The hope was to better this state of affairs by familiarizing the audience with some of the major controversies surrounding CAIM research and its regulation.

As it turned out, NCCAM, itself came in for censure. Dr Daniel Cherkin, Associate Director for Research and Senior Investigator at Group Health in Seattle functioned as moderator and began the program with a catalog of ills from which the US health care system suffers, a description of the role CAIM has played in responding to those ills, a review of NCCAM's mission and several questions regarding how that mission has been and should be carried out. A standing-room-only crowd then heard Dr Donald Marcus, Professor of Medicine at Baylor University and well-known CAIM critic and Dr John Longhurst, Director of the Susan Samueli Center for Integrative Medicine and Professor of Medicine at the University of California at Irvine deliver their appraisals of NCCAM. They decried the 'too-low' ratio of basic to clinical research, what they view as the inordinate

For reprints and all correspondence: Elizabeth H. Logue,

CRNP Fellow, UCLA Center for East West Medicine, 2428 Santa

Monica Blvd. Suite 208, Santa Monica, CA 90404. Tel: 310-998-9118;

Fax: 310-829-9318; E-mail: elogue@mednet.ucla.edu influence on the Advisory Council and review panels of CAIM practitioners, many of whom lack research training and the investigation of 'scientifically implausible' therapies for which there is inadequate preliminary data and which, in some cases may be dangerous. NCCAM's EDTA chelation trial was mentioned as being especially ill-advised. While largely critical, both speakers' remarks included some praise. Dr Marcus made reference to neuroscientific studies, work on the placebo effect and negative trials of herbs as useful NCCAM achievements. Dr Longhurst spoke of NCCAM's unique role in investigating modalities ignored by the rest of $\mathrm{NIH}$. Although he favors continued research on some CAIM treatments, Dr Marcus opined that other NIH Centers are equipped to take on such projects. He repeated his call for an outside review of NCCAM, citing his belief that political rather than scientific considerations drive its agenda. He regards the situation as untenable, particularly in an era of major cutbacks in research funding. While not calling for an independent review, Dr Longhurst spoke strongly in favor of reform, a narrowing of the research agenda as well as an increase in funding.

While Professors Longhurst and Marcus gave an overview of the field of CAIM research, Dr Ary Goldberger, Director of the Margret \& H. A. Rey Institute for Nonlinear Dynamics in Medicine at Boston's Beth Israel Deaconess Medical Center and Professor of Medicine at Harvard Medical School discussed his work on complex systems as one example of where such research may be headed. In Dr Goldberger's view, conventionally designed studies frequently err in focusing on only one molecular mechanism, ignoring communication among pathways and sometimes leading to unforeseen adverse outcomes. Dr Goldberger suggested that conservatism in science extends to the underlying approach to physiological systems, often wrongly privileging homeostasis ("constancy as the wisdom of the body') over complex adaptability, multi-scale 
dynamics and emergent properties. In as much as they are non-linear, non-stationary, non-additive and show time irreversibility, however, complex systems may be inaccessible to conventional analytic techniques, according to the speaker. Dr Goldberger left the impression that he believes both investigators and NIH Centers in general ought to be more open to novel but rigorous research designs and methodology.

On the subject of the criticisms leveled at NCCAM, the speaker advocated 'ruthless neutrality' in all scientific investigation but suggested that in its imperfection, NCCAM in no way distinguishes itself from other NIH Centers. He criticized the NIH system, generally, for a tendency to reward 'specific-aimsmanship' in grant writing over originality. He advocated the same nonlinearity of thought for the NIH that his work has shown to be associated with good bodily health and adaptability to stress. In noting that taxpayers 'own' NIH data, Dr Goldberger suggested that NCCAM take a leadership role in advocacy for open access data and open source software, fostering scientific collaboration by allowing validation of studies already completed.

NCCAM and CAIM leaders and investigators have countered several of the arguments made by speakers Longhurst and Marcus in the past (2-10) and UCLA panelists echoed some of those responses, adding queries of their own. Professor-in-Residence Mark Cohen expressed the view that current research tools may be inadequate for measuring the effects of some CAIM treatments. In addition, he noted that taxpayers already support faithbased initiatives and questioned whether conventional science has a 'special entitlement' to public funds, given that orientation. On the issue of the research agenda at NCCAM, he made mention of the fact that in creating the R21 grant, NIH acknowledged that existing funding mechanisms didn't sufficiently encourage creativity. With regard to political considerations, he pointed out that these have played a role in the creation of other NIH Centers, including the National Institute of Biomedical Imaging and BioEngineering (NIBIB). Noted UCLA cancer researcher Dr Patricia Ganz seconded Cohen's concern about conservatism at NIH, recounting difficulties convincing colleagues and reviewers of the need to study links between the mind and body. She decried many investigators' unwillingness to 'think outside the heart', a reference to her observation that most rarely emerge from their disciplinary 'silos'. Dr Marcus agreed on the importance of supporting some mind-body research, but indicated he felt that funders have turned a corner and are now more open to such work. Drs Ganz and Longhurst both spoke in favor of the training of more persons capable of doing rigorous science across disciplines.

Distinguished Professor Edwin Cooper (Editor in Chief, Evidence Based Complementary and Alternative Medicine) echoed others' reluctance to single out NCCAM for castigation. He, too, raised questions about what passes for good research methodology, asking whether studying ancient, whole systems of medicine using Western, reductionistic techniques doesn't strip them of essential features. Associate Professor of Pediatrics, Jennie Tsao agreed on the importance of investigating traditional medicine as practiced remarking that for most usersusers in India and China, for example - such therapies are not considered 'alternative'. Dr Ganz added that some non-western practices are associated with greater longevity and may merit study as potential models for biomedicine as it faces an epidemic of chronic disease. On the subject of NCCAM's achievements, Dr Tsao, suggested taking the long view. She noted that psychological treatments such as cognitive-behavioral therapy (CBT) now have an established evidence base, thanks largely to sponsorship by the National Institute of Mental Health (NIMH). However, it took many years to separate empirically validated approaches from those with little or no value. Thus, to summarily dismiss a whole group of therapies as unsupported would be premature, in her view. Dr Alison Moore, an authority on geriatric alcoholism questioned speakers on funding alternatives outside of NIH and opportunities for training in CAIM research. Participants acknowledged the difficulty of finding research dollars and Dr Longhurst named several non-governmental sources he had used, suggesting that young investigators look to such funding as a bridge to support by NIH. After summarizing points made by the speakers and panelists, Dr Cherkin concluded that there is a need to broaden our view of what constitutes good science and that systems-level investigations and a focus on patients' concerns as they view them are important means of achieving that end.

'Science of CAIM' was unusual in that it brought together experts representing widely divergent opinions on how complementary, alternative and integrative modalities should be studied for a face-to-face discussion. While consensus was not reached on most issues, the symposium did succeed in offering those in the business of evaluating CAIM proposals exposure to some of the most pressing questions regarding its study and regulation, thereby addressing concerns expressed in NCCAM's Strategic Plan. A pod cast of the symposium is available at http://www.cewm.med.ucla.edu/podcasts/index.html

\section{References}

1. National Center for Complementary and Alternative Medicine. Expanding Horizons of Health Care Strategic Plan 2005-2009. Bethesda, Maryland: U.S. Department of Health and Human Services.

2. Marcus DM, Grollman AP. Review for NCCAM is overdue. Science 2006;313:301-2.

3. Straus SE, Chesney MA. In defense of NCCAM. Science 2006;313:303-4. (author reply 1083-4). 
4. Folkman S, Berman B, Bondurant S, Eisenberg D, Haramati A, Kreitzer MJ. Debating the worth of NCCAM research. Science 2006;314:1083. (author reply 1083-4).

5. Lewith G, Verhoef M, Koithan M, Zick SM. Developing CAM research capacity for complementary medicine. Evid Based Complement Alternat Med 2006;3:283-9.

6. Lewith G. Complementary medicine research unit. Evid Based Complement Alternat Med 2005;2:399-407.

7. Boon H, Macpherson H, Fleishman S, Grimsgaard S, Koithan M, Norheim AJ, et al. Evaluating complex healthcare systems: a critique of four approaches. Evid Based Complement Alternat Med 2007;4:279-85.
8. Chiappelli F, Prolo P, Cajulis OS. Evidence-based research in complementary and alternative medicine I: history. Evid Based Complement Alternat Med 2005;2:453-8.

9. Fonnebo V, Grimsgaard S, Walach H, Ritenbaugh C, Norheim AJ, MacPherson $\mathrm{H}$, et al. Researching complementary and alternative treatments - the gatekeepers are not at home. BMC Med Res Methodol 2007;7:7.

10. Lewith GT, Verhoef MJ. The International Society for Complementary Medicine Research (ISCMR): the way forward. Evid Based Complement Alternat Med 2006;3:157-8.

Received March 24, 2008; accepted April 4, 2008 


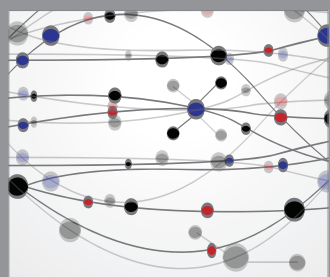

The Scientific World Journal
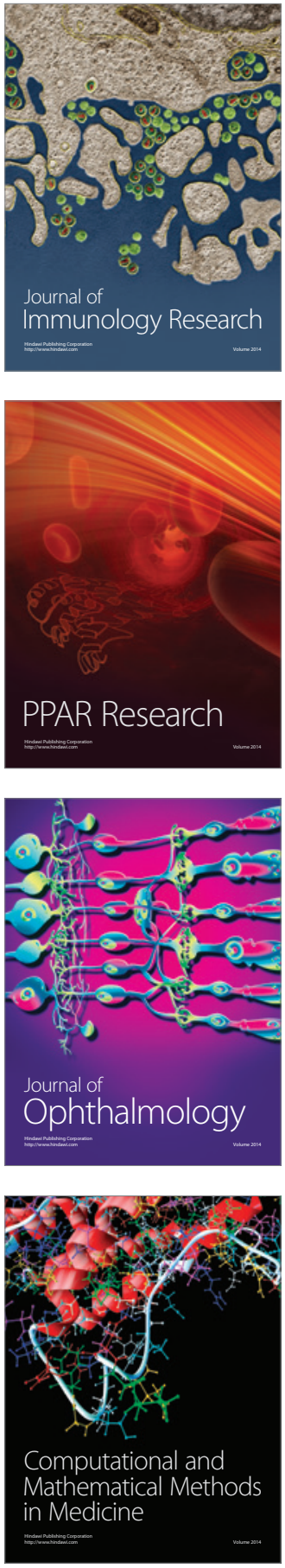

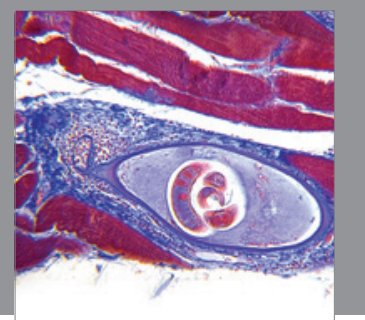

Gastroenterology

Research and Practice
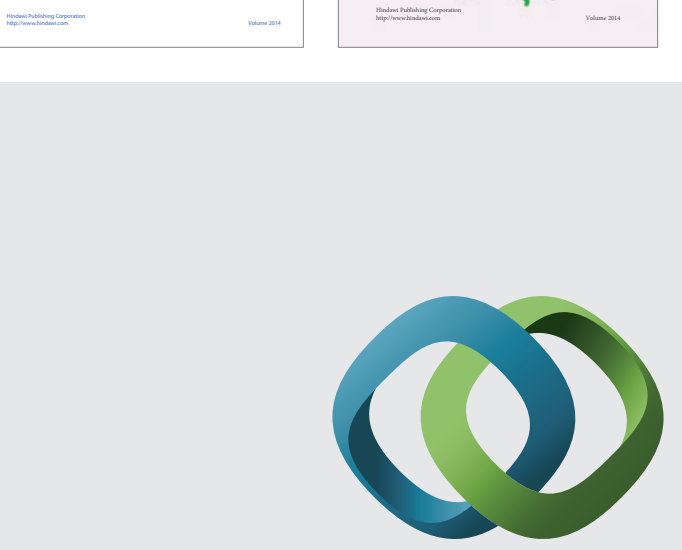

\section{Hindawi}

Submit your manuscripts at

http://www.hindawi.com
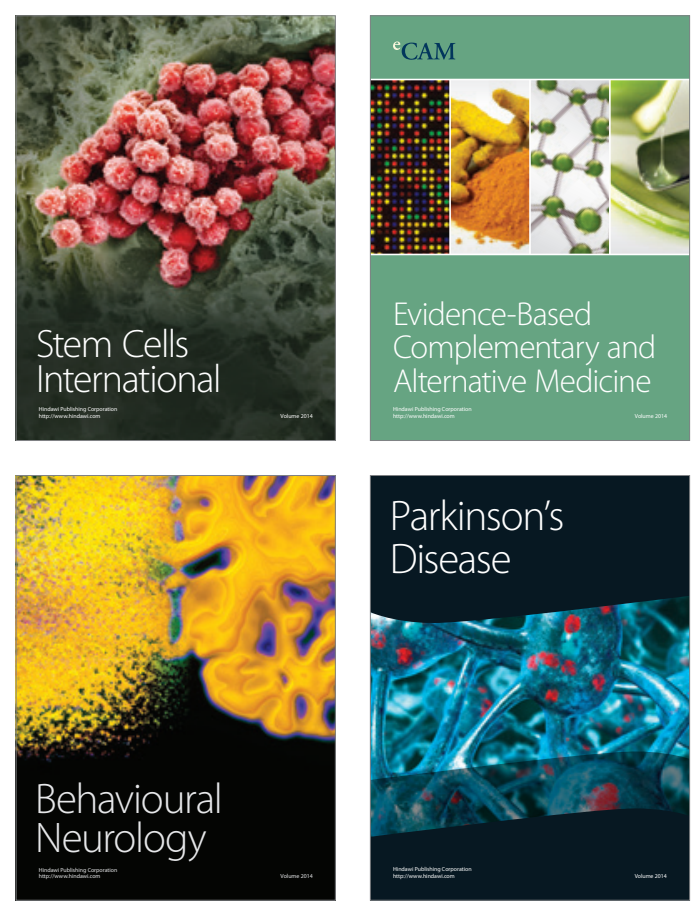

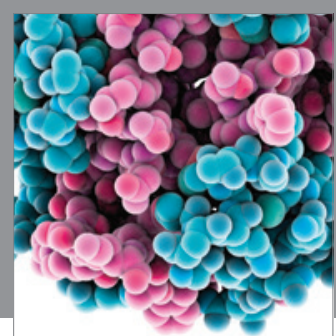

Journal of
Diabetes Research

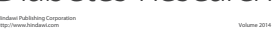

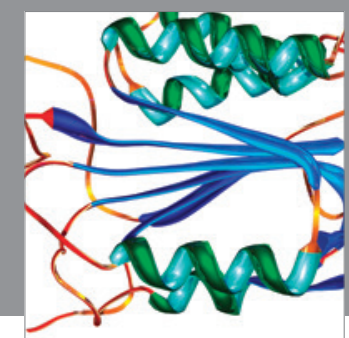

Disease Markers
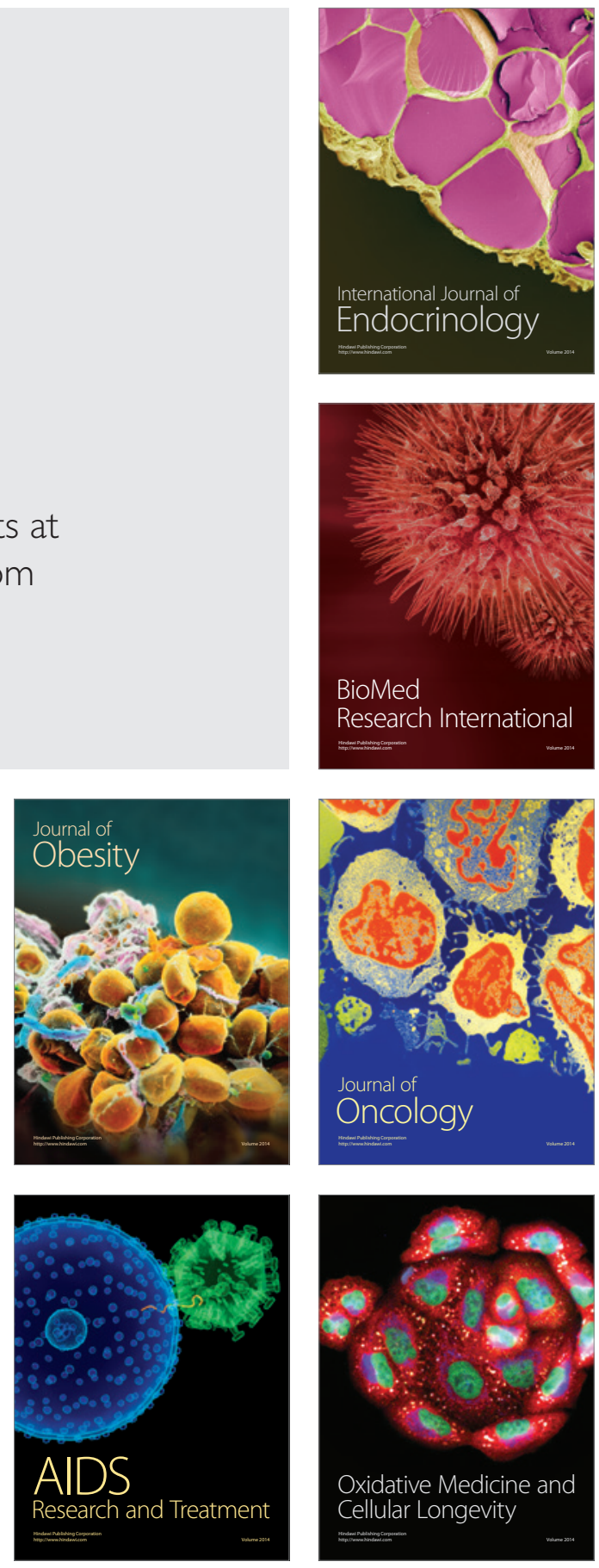